\title{
The Influence of Dissolved Oxygen on Pseudomonas AM1 Grown on Methanol in Continuous Culture
}

\author{
By D. G. MACLENNAN,* J. C. OUSBY, R. B. VASEY AND N. T. COTTON \\ Imperial Chemical Industries Limited, Agricultural Division, \\ Billingham, Teesside
}

(Accepted for publication 20 September 1971)

\begin{abstract}
SUMMARY
Methanol-limited cultures of Pseudomonas AM I were grown in chemostats $\left(D, 0 \cdot \mathrm{I} \mathrm{h} .^{-1}\right.$; methanol IO g./l.) at dissolved oxygen tensions between I and $690 \mathrm{~mm}$. $\mathrm{Hg}$. Decreasing the dissolved oxygen tension from 110 to $28.5 \mathrm{~mm}$. $\mathrm{Hg}$ did not affect either respiration or carbon balance, but lowering it further caused a progressive increase in respiration which was maximal at $3 \mathrm{~mm}$. $\mathrm{Hg}$ (the lowest dissolved oxygen tension at which a steady state could be maintained at the fixed dilution rate). Increasing the dissolved oxygen tension from 97 to $560 \mathrm{~mm}$. $\mathrm{Hg}$ increased production of $\mathrm{CO}_{2}$ and decreased yield; this effect was particularly evident between 420 and $560 \mathrm{~mm}$. $\mathrm{Hg}$. Yield varied little between 560 and $690 \mathrm{~mm}$. $\mathrm{Hg}$ but $\mathrm{CO}_{2}$ output decreased and exocellular products increased in concentration indicating a metabolic change. The possible mechanisms involved in metabolic regulation are discussed; it is concluded that dissolved oxygen tensions between $3 \mathrm{~mm}$. and $690 \mathrm{~mm}$. Hg exert a continuous quantitative control over respiration and metabolism of growing organisms. A stoichiometric equation is derived for the growth of Pseudomonas AM I on methanol.
\end{abstract}

\section{INTRODUCTION}

The increasing importance of single cell protein, both for animal and human consumption, has stimulated much interest in the design of large continuous fermenters with hitherto unprecedented rates and efficiencies of $\mathrm{O}_{2}$ transfer. Oxygen transfer in an aerated fermenter is achieved most efficiently when the partial pressure of $\mathrm{O}_{2}$ in the gas phase is high and the dissolved oxygen tension (DOT) is low. However, the influence of these conditions on the growth and physiology of the micro-organisms in the culture needed to be assessed.

Much work has been published on the effects of low DOT on micro-organisms, but generally this was done either on washed suspensions of organisms or else before reliable DOT electrodes were available. In the former case neither the influence of growth rate nor the adaptive response of the culture to DOT can be taken into account; the importance of both of these factors has been discussed by Harrison, MacLennan \& Pirt (1969). The most effective way of studying the influence of DOT is to study growing organisms cultivated under steady-state conditions at a constant dilution rate (growth rate) in continuous culture, while maintaining the DOT at a constant level. Experiments of this type have been reported by Harrison \& Pirt (1967), Harrison et al. (1969) and Moss, Rickard, Beech \& Bush (1969) in which the results obtained differed greatly from those reported using washed cell suspensions. These workers showed that with Klebsiella aerogenes, Pseudomonas DX 2 and

* Present address: Department of Chemical Engineering, University of Sydney, N.S.W., Australia. 
Candida utilis, respectively, the critical DOT* depends very much on the culture conditions. Also, at DOT below the critical value, these organisms exhibited an adaptive response in the form of either a stimulation of $\mathrm{O}_{2}$ uptake or an increase in affinity for oxygen. MacLennan \& Pirt (1970) also studied the influence of DOT on the carbon balance with Pseudomonas DX 2 grown on decane and on glucose and found that in neither case did the critical DOT (which was different with each substrate) coincide with the DOT at which significant changes in carbon balance occurred. The response of micro-organisms to lowered DOT is thus highly complex and much is yet to be learned about the mechanisms involved.

Although it is generally known that hyperbaric oxygen has an effect on the growth and behaviour of micro-organisms (see reviews by Wimpenny, I969; ZoBell, I970), no quantitative work relating hyperbaric dissolved oxygen tension to either respiration or carbon distribution has been reported.

The object of this work was to study quantitatively the influence of DOT, over a wide range, on the physiology of a micro-organism growing on methanol in continuous culture; we report here the effect of DOT on respiration, and on metabolism as evidenced by the distribution of methanol-carbon between cells, $\mathrm{CO}_{2}$ and extracellular products.

\section{MATERIALS}

Organism. Pseudomonas AM I, NCIB9I33 (obtained from National Collection of Industrial Bacteria) was re-isolated from a chemostat culture after 3 weeks growth in methanol-limited medium. It was maintained on methanol agar slopes.

Media. The continuous culture medium contained (g./1.): $\mathrm{H}_{3} \mathrm{PO}_{4}, 0.65 ;\left(\mathrm{NH}_{4}\right)_{2} \mathrm{SO}_{4}, 3.6$; $\mathrm{MgSO}_{4} .7 \mathrm{H}_{2} \mathrm{O}, 0.45 ; \mathrm{FeSO}_{4} .7 \mathrm{H}_{2} \mathrm{O}, 2 \times \mathrm{IO}^{-3} ; \mathrm{CuSO}_{4} .5 \mathrm{H}_{2} \mathrm{O}, 4 \times 10^{-5} ; \mathrm{H}_{3} \mathrm{BO}_{3}, 3 \times \mathrm{IO}^{-5} ;$ $\mathrm{MnSO}_{4} \cdot 4 \mathrm{H}_{2} \mathrm{O}, 2 \times \mathrm{IO}^{-4} ; \mathrm{ZnSO}_{4} \cdot 7 \mathrm{H}_{2} \mathrm{O}, 2 \times \mathrm{IO}^{-4} ; \mathrm{Na}_{2} \mathrm{MoO}_{4}, 4 \times \mathrm{IO}^{-5} ; \mathrm{CaCl}_{2} \cdot 2 \mathrm{H}_{2} \mathrm{O}, 5 \cdot 3 \times$ $\mathrm{IO}^{-3} ; \mathrm{CoCl}_{2} \cdot 6 \mathrm{H}_{2} \mathrm{O}, 4 \times \mathrm{IO}^{-5}$. The $\mathrm{pH}$ was $2 \cdot 83$. This medium was sterilized in $20 \mathrm{l}$. quantities by autoclaving at $\mathrm{I} 5 \mathrm{lb}$./in. ${ }^{2}$ for $60 \mathrm{~min}$. The carbon source was prepared separately as a $50 \%$ $(\mathrm{w} / \mathrm{v})$ solution of methanol (purity $>99.9 \%$ ) in distilled water and was sterilized in 201 . quantities by autoclaving at $15 \mathrm{lb}$./in..$^{2}$ for $30 \mathrm{~min}$.

The medium used for seed cultures contained the above mineral salts medium at half concentration, with the $\mathrm{H}_{3} \mathrm{PO}_{4}$ replaced by $\mathrm{K}_{2} \mathrm{HPO}_{4}\left(\mathrm{I} \cdot 90 \mathrm{~g}\right.$./l.) and $\mathrm{NaH}_{2} \mathrm{PO}_{4} \cdot 2 \mathrm{H}_{2} \mathrm{O}$ ( .56 g./1.); the $\mathrm{pH}$ was 6.85 . Sterile methanol $(0.5 \%, \mathrm{v} / \mathrm{v})$ was added to the mineral salts medium. Solid medium was prepared by adding agar $(\mathrm{I} \cdot 5 \%, \mathrm{w} / \mathrm{v})$ to seed medium.

Continuous culture equipment. A chemostat was used which had a culture vessel similar in design to that of Elsworth, Meakin, Pirt \& Capell (1956), and a working volume of $2 \cdot 751$. A vaned-disc impeller ( $64 \mathrm{~mm}$. diameter) was used, rotated at $1500 \mathrm{rev} . / \mathrm{min}$. Mineral salts medium and methanol solution were pumped separately into the fermenter using Sigmamotor models T6S and T8 pumps, respectively (V. A. Howe Co. Ltd, London, W. II). Neoprene tubing ( $1.0 \mathrm{~mm}$. bore) was used for the methanol feed line. The $\mathrm{pH}$ was automatically controlled to within $\pm 0 . \mathrm{IH}$ units by the addition of $\mathrm{CO}_{2}$-free $4 \mathrm{~N}-\mathrm{KOH} / 4 \mathrm{~N}$ $\mathrm{NaOH}$ solution (I : I mixture) via a DCL Series III Micropump (F. A. Hughes Co. Ltd, Epsom, Surrey). Foam was controlled by automatic addition of $0.05 \mathrm{ml}$. Dow Polyglycol P-2000 (Dow Chemical Co. Ltd, London, W. I) every hour.

Measurement and control of DOT. Dissolved oxygen tension was measured, and manually or automatically controlled, as described by MacLennan \& Pirt (I966). For work at low DOT a constant flow of $\mathrm{N}_{2}$ was used as carrier gas and the DOT controlled by regulation of the flow of air. At high DOT the carrier gas was air and the control gas was $\mathrm{O}_{2}$. Measurement

* Generally defined as the DOT above which respiration $\left(q \mathrm{O}_{2}\right)$ is independent of DOT. 


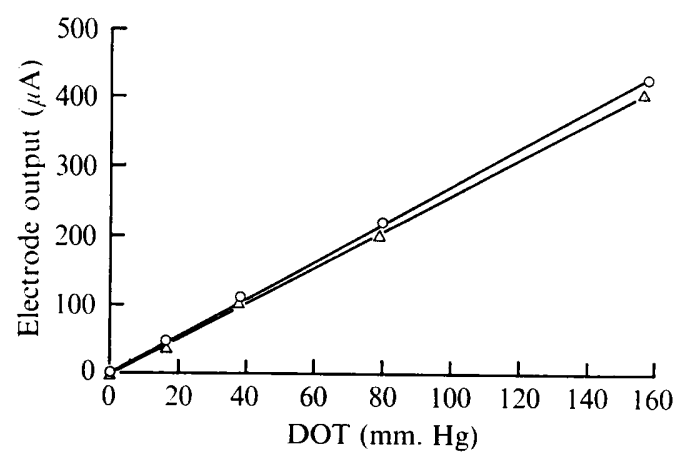

Fig. I

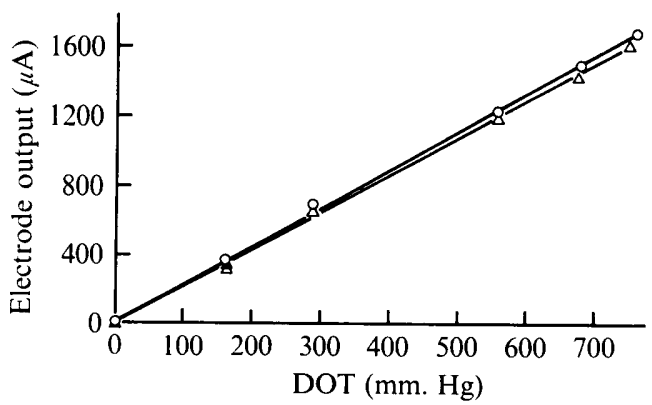

Fig. 2

Fig. I. Calibration curves for Mackereth DOT electrode used during experiments at low DOT. $O-O$, Initial calibration; $\triangle-\triangle$, final calibration 42 days later.

Fig. 2. Calibration curves for Mackereth DOT electrodes used during experiments at hyperbaric DOT. $\bigcirc-O$, Initial calibration of first electrode; $\boldsymbol{\Delta}$, check on initial calibration of second electrode at $\mathrm{I} 57 \mathrm{~mm} . \mathrm{Hg} ; \triangle-\triangle$, final calibration of second electrode 23 days after initial calibration.

of DOT was with Mackereth-type electrodes (model A I5 A, Laboratory Oxygen Electrode, Electronic Instruments Ltd, Richmond, Surrey), which were calibrated in sterile medium (at $30^{\circ}$ ) in equilibrium with gases of known composition. From calibration curves (Figs. I, 2) it can be seen that invariably the output current from the electrode at zero DOT was undetectably low, and the calibration was linear with DOT. Fig. I also shows that in experiments at low DOT the sensitivity of the electrode dropped by only $4.5 \%$ over a 6 -week period of continuous operation. In the hyperbaric DOT experiments the electrode was replaced after 24 days operation with a freshly prepared electrode, the calibration of which had been checked in another fermenter. It can be seen (Fig. 2) that the initial calibration of the first electrode and the initial and final calibrations of the second electrode (recalibrated 23 days after insertion) all agreed to within $\pm 3 \%$.

Gas measurement equipment. The flow of gases (air, $\mathrm{N}_{2}, \mathrm{O}_{2}, \mathrm{CO}_{2}$ ) into the fermenter was measured using individually calibrated Rotameters (Rotameter Manufacturing Co. Ltd, Croydon, Surrey) which were accurate to within $\pm 2 \%$. The total effluent gas flow rate was measured using a Water Displacement Rotary Gas Meter (model PGM-1 ; Fison's Scientific Apparatus Co. Ltd, Loughborough, Leicestershire) with an accuracy of $\pm 2 \%$, and continuously recorded. The partial pressure of $\mathrm{O}_{2}$ in the effluent gas was then measured by a DCL model 137 A Paramagnetic Oxygen Analyser (Servomex Controls Ltd, Crowborough, Sussex), with an accuracy of $\pm \mathrm{I} \%$, and continuously recorded. The partial pressure of $\mathrm{CO}_{2}$ was measured with either an IRDA Infra Red Analyser (Sir Howard Grubb Parsons \& Co. Ltd, Newcastle upon Tyne) or a LIRA model 300 Infra Red Analyser (Mine Safety Appliances Co. Ltd, Maidenhead, Berkshire), with an accuracy of $\pm 2 \%$, and also recorded continuously. The instruments were calibrated against standard gas mixtures each day and the overall accuracy of the gas system was such that in the absence of culture, the composition and flow rate of the effluent gas, as measured by the analytical instruments described, agreed with that of the Rotameter system to within $\pm 2 \%$ over the entire working range of the system.

Cultural conditions. The organism was grown at a dilution rate of $0 \cdot 1$ h. ${ }^{-1}$ with methanol (Io g./1.) as the growth-limiting substrate, unless otherwise stated. The $\mathrm{pH}$ was automatically 
controlled at 6.8 and the temperature at $30^{\circ}$. The partial pressure of $\mathrm{CO}_{2}$ in the effluent gas was maintained between $\mathrm{I} \%$ and $5 \%$.

Analytical procedures. Bacterial dry weights were determined after centrifugation for $30 \mathrm{~min}$. at $18,000 \mathrm{~g}$ at $4^{\circ}$ washing with distilled water, recentrifuging and drying for $\mathrm{I} 6 \mathrm{~h}$. at $105^{\circ}$. Duplicate estimations agreed to within $\pm 2 \%$. Elemental carbon, hydrogen and nitrogen contents were determined on the biomass prepared as above, using an $\mathrm{F} \& \mathrm{M}$ Analyser (Hewlett-Packard Ltd, Slough, Buckinghamshire). The accuracy of the method is $\pm \mathrm{I} \%$ of the reading.

The concentration of methanol in the nominal $50 \%(\mathrm{w} / \mathrm{v})$ aqueous feed solution was determined, after sterilization, from the specific gravity. The accuracy was $\pm 0.05 \%$. The concentration of methanol in the culture extracellular fluid was determined by Vapour Phase Chromatography. Methanol assimilation subsequent to sampling was stopped by adding $0 . \mathrm{I} \mathrm{ml}$. of a saturated aqueous solution of $\mathrm{HgCl}_{2}$ to the Io ml. sample.

Carbon balance. The following was determined:

$$
\begin{aligned}
\mathrm{C}_{\text {methanol in }}-\mathrm{C}_{\text {residual methanol }} & =\mathrm{C}_{\text {methanol uptake }} \\
& =\mathrm{C}_{\text {cells }}+\mathrm{C}_{\mathrm{CO}_{\mathbf{2}}}+\mathrm{C}_{\text {extracellular non-methanol }}
\end{aligned}
$$

'Extracellular non-methanol carbon' as defined should represent only exocellular products. However, as it was determined by difference it also includes errors in any of the other carbon measurements. Thus great care was taken to achieve the highest accuracy in the measurement of all parameters so that the term should reflect exocellular products as closely as possible.

Dissolved $\mathrm{CO}_{2}$ and methanol lost by evaporation have not been included in the balance as experiments showed that, in both cases, the quantity involved was negligible.

\section{RESULTS}

The data was collected from two separate experiments: the first was concerned with DOT below about $100 \mathrm{~mm}$. $\mathrm{Hg}$ and the second with values above this level. In the first experiment a methanol-limited steady state was established at IIO $\mathrm{mm}$. $\mathrm{Hg}$ and carbon balances and respiration rates determined. The DOT was then decreased, another steady state established and the above data again determined. This procedure was repeated at progressively lower DOT's until steady-state conditions could no longer be established and the culture washed out. The second experiment, to determine the effect of high DOT, was similar except that the DOT was progressively increased from $97 \mathrm{~mm}$. $\mathrm{Hg}$.

\section{Influence of decreased dissolved oxygen tension}

The effects of decreasing DOT on some growth parameters are shown in Figs. 3 and 4 . Between IIO and $28.5 \mathrm{~mm}$. $\mathrm{Hg}$ no change occurred in any of these parameters, but when DOT was lowered below $28.5 \mathrm{~mm}$. $\mathrm{Hg}$, respiratory activity, as evidenced by total $\mathrm{O}_{2}$ uptake (indicated by 0.Q. ${ }^{*}$ ), $q \mathrm{O}_{2}$ and $q \mathrm{CO}_{2}$ (Fig. 3) increased. This change was consistent with the observed change in the carbon balance (Fig. 4), which showed that below $28.5 \mathrm{~mm}$. $\mathrm{Hg}$ the proportion of carbon converted to $\mathrm{CO}_{2}$ increased at the expense of extracellular nonmethanol carbon. When DOT was lowered from 7 to $3 \mathrm{~mm}$. $\mathrm{Hg}$ the bacterial mass decreased indicating that availability of $\mathrm{O}_{2}$ to the cell had become the growth limiting factor. This was confirmed by the appearance of increased quantities of residual methanol in the culture

* Oxidation quotient, defined as the mole ratio $\mathrm{O}_{2}$ Uptake: $\mathrm{CH}_{3} \mathrm{OH}$ Uptake. 


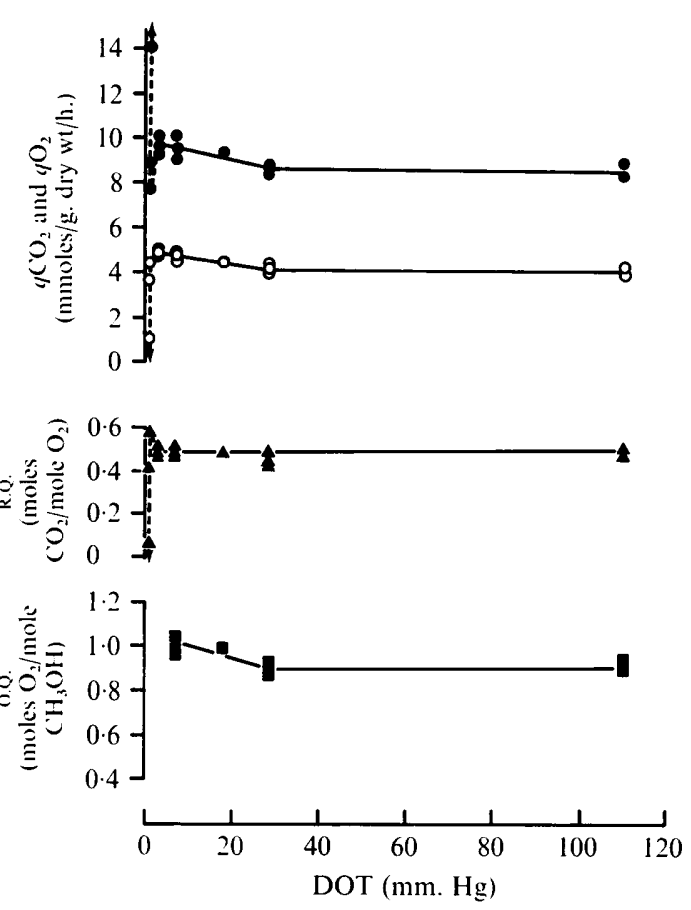

Fig. 3

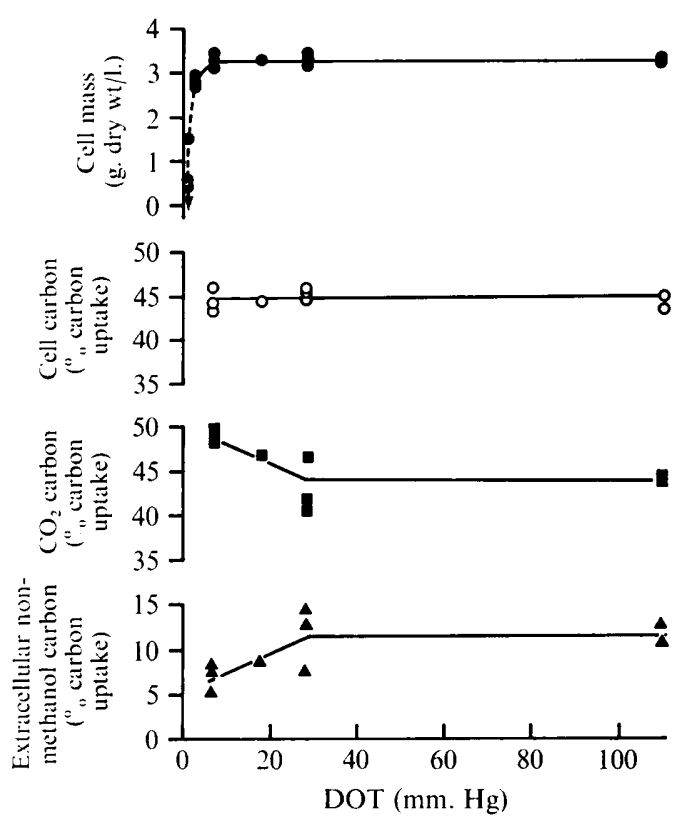

Fig. 4

Fig. 3. Respiratory activity of Pseudomonas AM I grown in steady state continuous culture ( $D$, $0 \cdot \mathrm{I} \mathrm{h} .^{-1} ; \mathrm{CH}_{3} \mathrm{OH}, \mathrm{IO}$ g./l.) at different DOT. The culture was methanol-limited at all DOT except 3 and $\mathrm{I} \mathrm{mm} . \mathrm{Hg}$ when cell growth was $\mathrm{O}_{2}$ limited. $-\mathrm{O}, q \mathrm{O}_{2} ; \mathrm{O}-\mathrm{O}, q \mathrm{CO}_{2} ; \Delta-\Delta$, respiratory quotient (R.Q.); $-\mathbf{\square}$, oxidation quotient (O.Q.). Dotted lines represent transient states. The limits of error in $q \mathrm{O}_{2}$ determinations, calculated from the accuracies of the gas measurement instruments, were $\pm 6 \%$ for DOT between I to $\mathrm{I} 8 \mathrm{~mm}$. Hg and $\pm 10 \%$ between 28.5 to $100 \mathrm{~mm}$. $\mathrm{Hg}(95 \%$ confidence levels).

Fig. 4. Graphs showing the carbon balances and cell mass of Pseudomonas AM I grown in steadystate continuous culture $\left(D, 0 . \mathrm{I} \mathrm{h}^{-1} ; \mathrm{CH}_{3} \mathrm{OH}, \mathrm{IO} \mathrm{g}\right.$./1.) at different DOT. The culture was methanollimited at all DOT except 3 and $\mathrm{I} \mathrm{mm} . \mathrm{Hg}$ when cell growth was $\mathrm{O}_{2}$-limited. - , Cell mass; $\mathrm{O}-\mathrm{O}$, carbon converted to cells; $\square-\square$, carbon converted to $\mathrm{CO}_{2} ; \boldsymbol{\Delta}-\mathbf{\Delta}$, extracellular nonmethanol carbon. Dotted lines represent transient states.

fluid, which, at all DOTs down to, and including, $7 \mathrm{~mm}$. $\mathrm{Hg}$, had been less than 20 p.p.m. Unfortunately quantitative analyses for methanol on samples at $3 \mathrm{~mm}$. $\mathrm{Hg}$ were lost and hence carbon balances at this DOT could not be calculated. It is interesting to note that despite the culture being $\mathrm{O}_{2}$-limited, at $3 \mathrm{~mm}$. Hg the specific respiratory activity $\left(q \mathrm{O}_{2}\right.$, $q \mathrm{CO}_{2}$ ) remained in the stimulated state. Finally, when DOT was reduced further, from 3 to I $\mathrm{mm}$. $\mathrm{Hg}$, washout occurred, indicating that oxygen limitation had decreased the growth rate of the culture to a value less than the dilution rate $\left(0^{\circ} \mathrm{I} \mathrm{h} .^{-1}\right)$. This was confirmed by the presence of rapidly increasing amounts of methanol in the culture supernatant.

\section{Influence of increased dissolved oxygen tension}

The effects of increasing the dissolved oxygen tension on some growth parameters are summarized in Fig. 5 and 6 . Between 97 and $420 \mathrm{~mm}$. Hg the culture was influenced by DOT, but not greatly. The proportion of carbon converted to biomass decreased gradually with increasing DOT while that converted to $\mathrm{CO}_{2}$ showed a gradual increase. The values of $q \mathrm{O}_{2}$, 


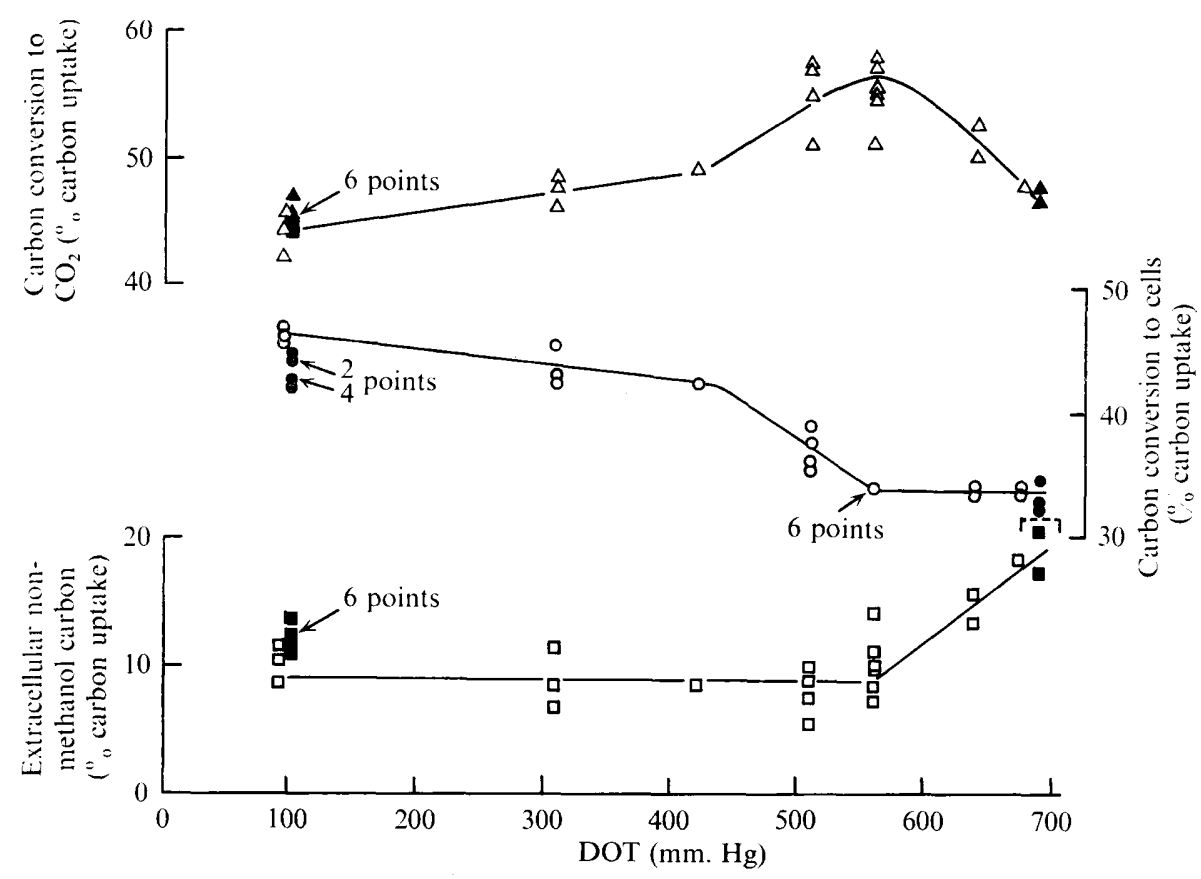

Fig. 5. Graph showing carbon balances for Pseudomonas AM I grown in carbon-limited steady-state continuous culture $\left(D, 0 \cdot \mathrm{I} \mathrm{h}^{-1} ; \mathrm{CH}_{3} \mathrm{OH}, \mathrm{I} O \mathrm{~g} . / 1\right.$. $)$ at different DOT. $\triangle, \Delta$, Carbon converted to $\mathrm{CO}_{2}$; $\bigcirc, \Theta$, carbon converted to cells; $\square, \boldsymbol{\square}$, extracellular non-methanol carbon. Filled symbols represent steady states which were repeated at a later stage in the experiment to confirm original points.

respiratory quotient (R.Q.) and oxidation quotient (O.Q.) did not change significantly. Between 420 and $560 \mathrm{~mm}$. $\mathrm{Hg}$ this trend was greater: the proportion of carbon converted into organism decreased more rapidly, while the carbon appearing as $\mathrm{CO}_{2}$ showed a corresponding increase (Fig. 5). This suggests that the organism was oxidizing larger proportions of methanol to $\mathrm{CO}_{2}$ and $\mathrm{H}_{2} \mathrm{O}$ at the expense of cell production, possibly in an attempt to lower the intracellular level of $\mathrm{O}_{2}$ to a non-toxic value. If this was so, then it would be expected that the $q \mathrm{O}_{2}$ would show a corresponding increase and, as can be seen (Fig. 6) this did occur. It can also be seen that the $q \mathrm{O}_{2}$ above $420 \mathrm{~mm}$. $\mathrm{Hg}$ was erratic and failed to reach a steady level over a period of 5 days at $510 \mathrm{~mm} . \mathrm{Hg}$ and 7 days at $560 \mathrm{~mm}$. $\mathrm{Hg}$, despite reasonable steady states being obtained with other parameters (see Fig. 7). Unfortunately, the large errors involved in $q \mathrm{O}_{2}$ determinations (as indicated in Fig. 6) at these high levels of dissolved oxygen makes the interpretation of the erratic behaviour of $q \mathrm{O}_{2}$ very difficult, although there is no doubt that the $q \mathrm{O}_{2}$ increased markedly at both 510 and $560 \mathrm{~mm}$. $\mathrm{Hg}$. The values of R.Q. and O.Q. were also erratic above $420 \mathrm{~mm}$. $\mathrm{Hg}$, due to their dependence on the accuracy of measurement of $\mathrm{O}_{2}$ uptake.

The behaviour of the culture at high DOT (above $560 \mathrm{~mm}$. $\mathrm{Hg}$ ) was particularly interesting. When DOT was increased up to $675 \mathrm{~mm}$. $\mathrm{Hg}$ the amount of methanol carbon being converted to cellular carbon did not vary but the $\mathrm{CO}_{2}$ output decreased and the extracellular non-methanol carbon, which had previously not changed significantly, increased. It would thus appear that the cells had undergone a further change in metabolism which enabled them to cope with the higher DOT without greater use of the detoxification mechanism involving oxidation of $\mathrm{CH}_{3} \mathrm{OH}$ to $\mathrm{CO}_{2}$. In fact, the activity of this mechanism appeared to 


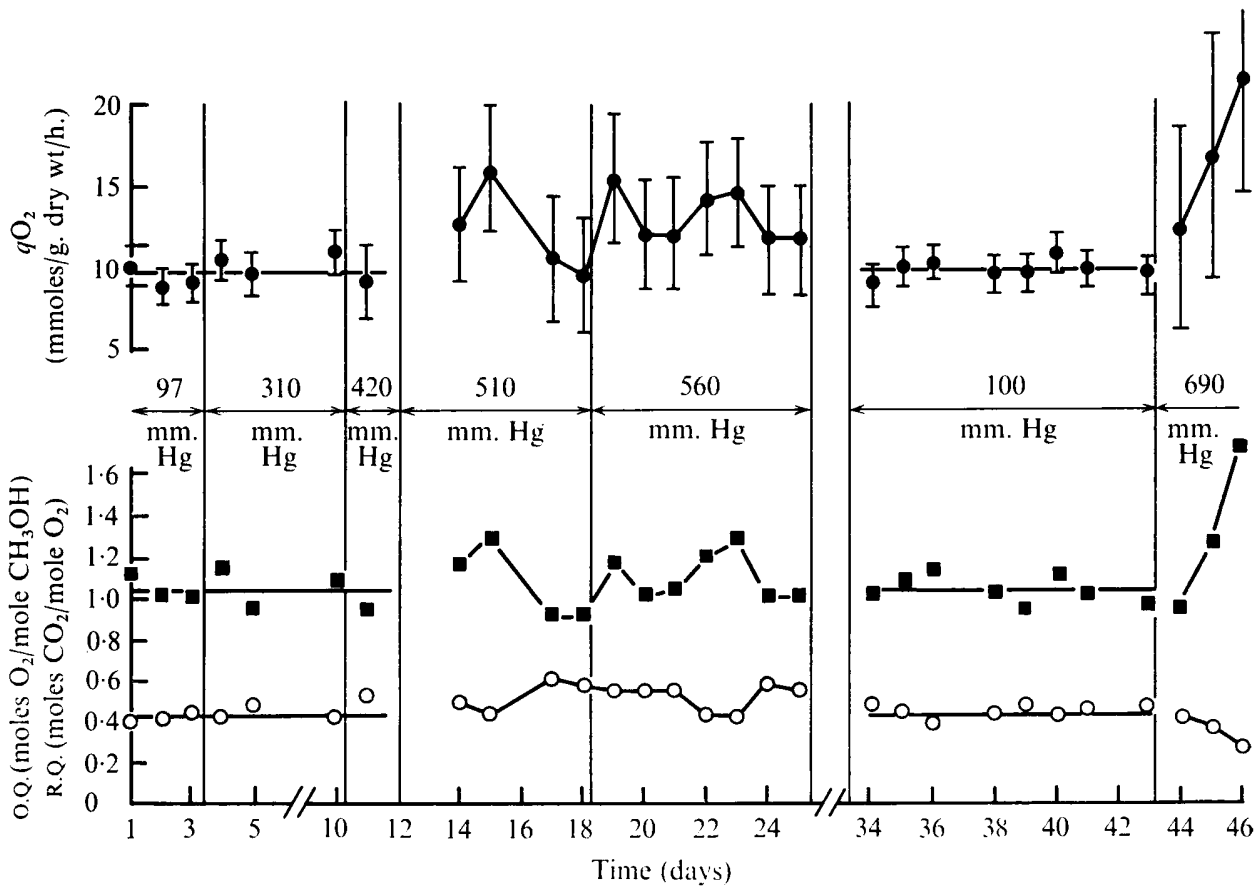

Fig. 6. Respiratory activity of Pseudmonoas AM I grown in carbon-limited continuous culture ( $D$, $0 . \mathrm{I} \mathrm{h} .^{-1} ; \mathrm{CH}_{3} \mathrm{OH}, \mathrm{IO} \mathrm{g}$./l.) at different DOT. The parameters are plotted on a daily basis and include transient states. $-q \mathrm{O}_{2} ; \mathbf{-}-\mathbf{0}, \mathbf{Q} . ; \mathrm{O}-\mathrm{O}$, R.Q. The perpendicular lines through $q \mathrm{O}_{2}$ points represent the limits of error $(95 \%$ confidence level) in the determination of the parameter, calculated from the accuracies of the gas measurement instruments.

decrease with increasing DOT as evidenced by the continuing drop in $\mathrm{CO}_{2}$ output. Unfortunately, the large errors in measuring $\mathrm{O}_{2}$ uptake at these high DOT prevented meaningful values for $q \mathrm{O}_{2}$, R.Q. and o.Q. from being obtained. The observed increase in extracellular non-methanol carbon accompanying decreased $\mathrm{CO}_{2}$ production indicated the accumulation of increased quantities of products of a less oxidized state than $\mathrm{CO}_{2}$. The nature of these products has not yet been determined.

Some insight into the nature of the observed changes was obtained from the behaviour of the culture in the transient state after changes in DOT. At DOT between 97 and $510 \mathrm{~mm}$. $\mathrm{Hg}$ steady states were established within 24 h., however (Fig. 7) when DOT was increased from 510 to $560 \mathrm{~mm}$. $\mathrm{Hg}$ the proportion of methanol-carbon incorporated into organisms dropped (point A) and took a total of 2 days (seven generations) to reach steady state. A similar but more pronounced effect was observed when DOT was further increased to $640 \mathrm{~mm}$. $\mathrm{Hg}$ (point $\mathrm{B}$ ), a total of 3 days then being required to reach a steady state. Thus some profound phenotypic and/or genotypic changes were clearly occurring. To determine the reversibility of the observed changes, the DOT was lowered, in one step, from 675 to $100 \mathrm{~mm}$. Hg. Then (Fig. 8, point C) the proportion of methanol carbon incorporated into the organisms increased over 2 to 3 days before reaching steady state. However, the conversion of methanol carbon to cellular carbon finally reached was significantly lower than the value initially obtained at $97 \mathrm{~mm}$. $\mathrm{Hg}$ (35 days previously; see Fig. 5), although the $q \mathrm{O}_{2}$, R.Q. and O.Q. reverted to values which were not significantly different from those previously obtained (Fig. 6). A possible explanation for this behaviour is that during the course of the 


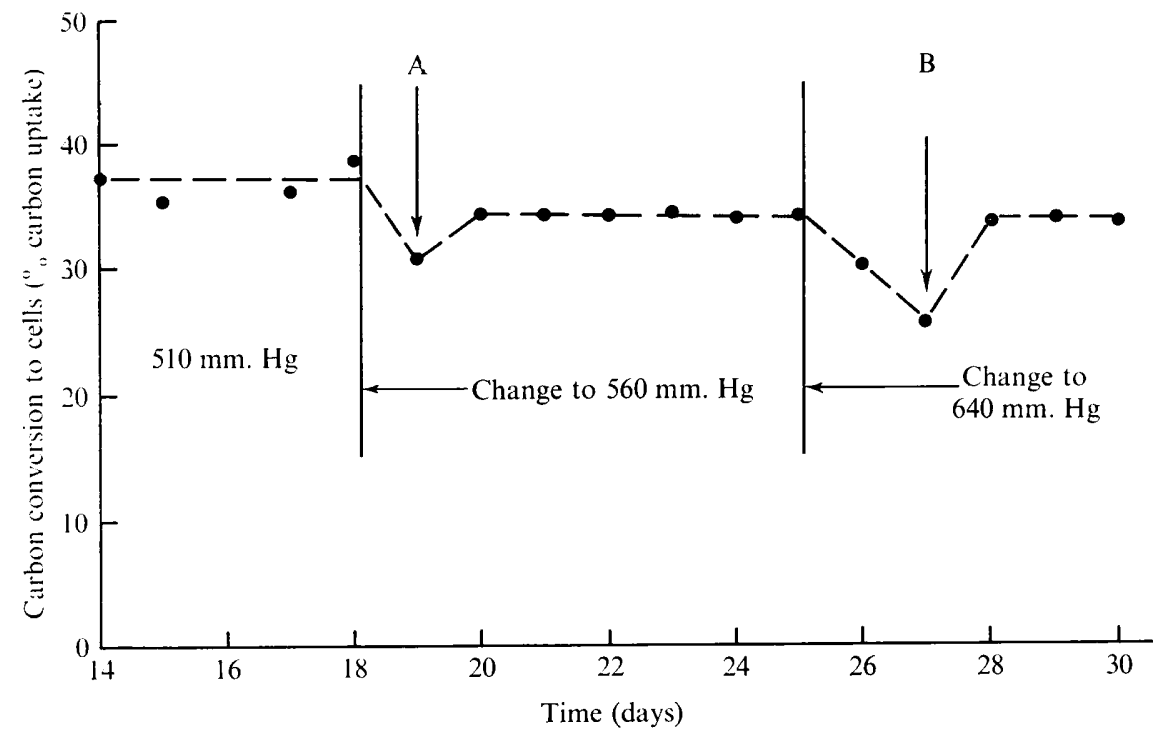

Fig. 7. Figure showing transient and steady state values of carbon-to-cell conversion in response to changed DOT for Pseudomonas AM I grown in carbon-limited continuous culture $\left(D, 0^{-} \mathrm{I} \mathrm{h}^{-1}\right.$; $\mathrm{CH}_{3} \mathrm{OH}$, ro g./1.). For explanation see text.

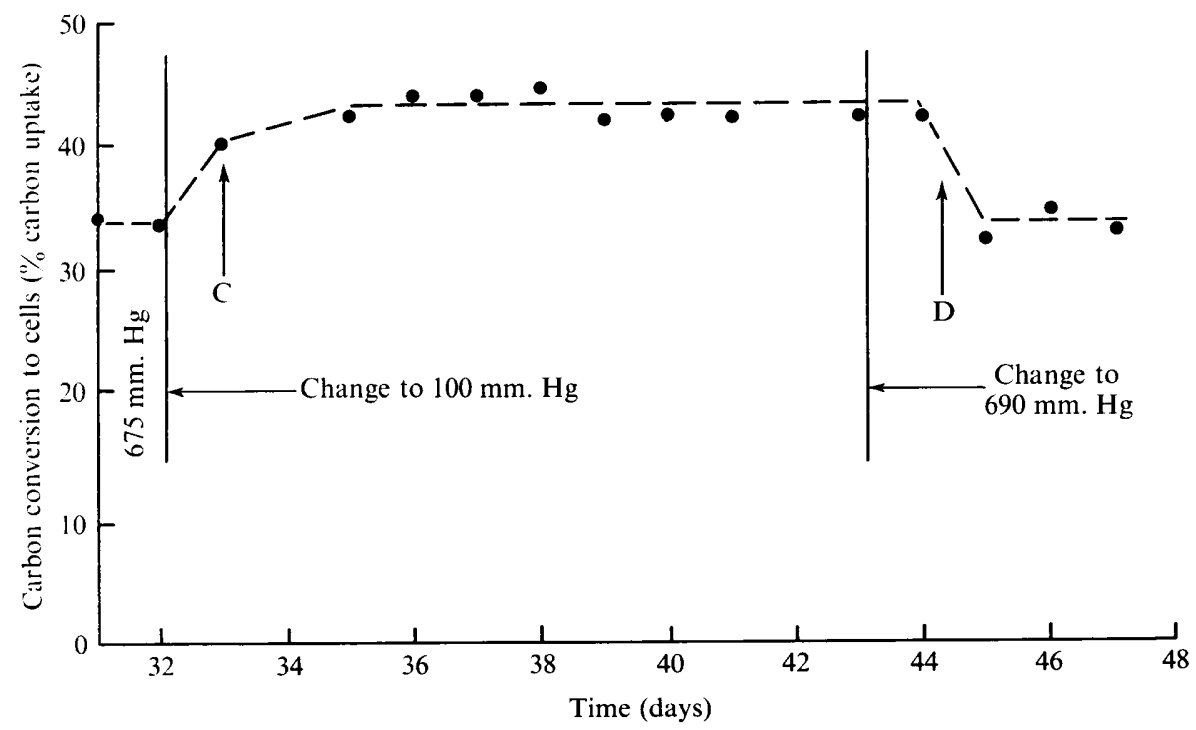

Fig. 8. Figure showing transient and steady-state values of carbon-to-cell conversion in response to changed DOT for Pseudomonas AM I grown in carbon-limited continuous culture $\left(D, 0^{\circ} \mathrm{I} \mathrm{h}^{-1}\right.$; $\mathrm{CH}_{3} \mathrm{OH}$, Io g./1.). For explanation see text.

experiment a variant had been selected which was better suited to growth at high DOT, but capable of growth (although less efficient) at lower DOT. If this were so it would be expected that if conditions of high DOT were again established then the culture would reproduce its performance both quickly and accurately. Accordingly the DOT was adjusted back, in one step, from 100 to $690 \mathrm{~mm}$. $\mathrm{Hg}$. It can be seen (Fig. 8, point D) that within 2 days a steady 
state was achieved without the initial drop in proportion of methanol carbon converted to cellular carbon observed previously. Also the carbon balance (Fig. 5) was in good agreement with that obtained at $675 \mathrm{~mm}$. Hg. However, although these results are consistent with a genotypic change, insufficient data are available to exclude an explanation based on phenotypic change, such as a hysteresis effect.

No experiments were done above $690 \mathrm{~mm}$. $\mathrm{Hg}$ as this was the highest DOT which could be achieved using pure $\mathrm{O}_{2}$ at atmospheric pressure as the aerating gas. The culture showed no signs of washout at this DOT and was still carbon-limited, the level of methanol in the supernatant fluid being less than 20 p.p.m.

\section{Stoichiometry of methanol oxidation by Pseudomonas AM I}

The stoichiometry of methanol oxidation by Pseudomonas AM I can be determined from the data in Fig. 3-6. However, it is clear that the equation depends very much on the growth conditions employed. The stoichiometry for the steady states in the region where DOT did not give rise to changes in growth (i.e. between 28.5 and $110 \mathrm{~mm} . \mathrm{Hg}$ ) is as follows:

$$
\text { I mole methanol+0.9 mole } \begin{aligned}
\mathrm{O}_{2} \rightarrow & 0.45 \text { mole cell carbon }+ \\
& 0.44 \text { mole } \mathrm{CO}_{2}+ \\
& 0.1 \text { m mole extracellular non-methanol carbon. }
\end{aligned}
$$

The elemental composition of the dried cells was $51 \cdot 1 \%$ carbon, $7 \cdot 2 \%$ hydrogen and $12 \cdot 2 \%$ nitrogen.

The presence of extracellular non-methanol carbon in the culture supernatant was verified by total carbon analyses, and although the nature of all of the compounds is not known, some of them arise from lysed cells.

\section{DISCUSSION}

The first response of the culture to decreased DOT was a stimulation of respiratory activity, which occurred at a value between 28.5 and $18 \mathrm{~mm}$. $\mathrm{Hg}$. Generally, the DOT at which growing cultures first show a respiratory change is lower $(7$ to $15 \mathrm{~mm}$. $\mathrm{Hg}$ ) and then respiratory activity decreases and not increases. Stimulation has been noted by Moss $e$ t al. (I969) with the yeast Candida utilis, although at a very much lower DOT $(<0.06 \mathrm{~mm}$. $\mathrm{Hg})$; and has also been observed by Harrison \& Pirt (1967) with Klebsiella aerogenes, where it appeared to form part of an indefinitely oscillating transient state at DOT below about Io $\mathrm{mm}$. Hg. However, this is the first time that it has been observed as a steady-state phenomenon at such high DOT. Physiologically the situation is interesting in that the cells are not limited by the quantity of $\mathrm{O}_{2}$ available (this being unlimited) but only by the potential at which it is available (i.e. DOT). It is possible that for the organism to maintain its growth under this constraint it requires more ATP and increases its respiration rate in order to increase its rate of oxidative phosphorylation. However, it is difficult to understand why, if a cell is still taking up at least the quantity of $\mathrm{O}_{2}$ it required at higher DOT, its internal metabolism should be influenced by DOT at all: unless the efficiency with which it can use $\mathrm{O}_{2}$ is a function of the potential at which it is available. This would suggest that the efficiency of oxidative phosphorylation is dependent on the level of DOT - oxidative phosphorylation becoming less efficient at these low DOT and a higher rate of respiration becoming necessary in order to maintain the ATP:ADP ratio at the required level.

The stimulation of respiratory activity observed as DOT was increased from 97 to $560 \mathrm{~mm}$. $\mathrm{Hg}$ presumably was accompanied by increased uncoupling of oxidative phosphorylation. However, in this case stimulated respiration was probably a mechanism to combat excessively 
high DOT - uncoupling of oxidative phosphorylation following to prevent over-production of ATP. A similar defensive mechanism has been reported by Hill, Drozd \& Postgate (I97I) to protect the $\mathrm{O}_{2}$-sensitive nitrogenase responsible for aerobic nitrogen fixation in Azotobacter chroococcum. The response above $560 \mathrm{~mm}$. $\mathrm{Hg}$ was totally unexpected, but is fully reproducible. It is paradoxical, however, that a change in metabolism aimed, presumably, at combating increasingly toxic levels of $\mathrm{O}_{2}$ should involve a decreased formation of fully oxidized carbon $\left(\mathrm{CO}_{2}\right)$ and an increased formation of partially oxidized products. More work is necessary to explain this apparently anomalous response.

The most striking aspect of the results reported here is the continuously changing response of the culture over the entire range of DOT studied. Such behaviour provides further confirmation of the concept originally put forward by Moss (1952, 1956) that micro-organisms are under continuous quantitative regulatory control of environmental oxygen concentration. However, the present work shows that the range of influence of DOT is much wider than has been considered previously and also that regulatory control is not restricted to facultative organisms but applies equally to strict aerobes.

\section{REFERENCES}

Elsworth, R., Meakin, L. R. P., Pirt, S. J. \& Capell, G. H. (1956). A two-litre scale continuous culture apparatus for micro-organisms. Journal of Applied Bacteriology 19, 264-278.

Harrison, D. E. F., Maclennan, D. G. \& Pirt, S. J. (1969). Responses of bacteria to dissolved oxygen tension. In Fermentation Advances, pp. I 17-144. Edited by D. Perlman. New York: Academic Press.

HARRISON, D. E. F. \& PIRT, S. J. (1967). The influence of dissolved oxygen concentration on respiration and glucose metabolism of $K$. aerogenes during growth. Journal of General Microbiology 46, I93-2I I.

Herbert, D. (1967). In Microbial Physiology and Continuous Culture, Proceedings of the 3rd International Symposium: Edited by E. O. Powell, C. G. T. Evans, R. E. Strange \& D. N. Tempest. London: H.M.S.O.

Hill, S., Drozd, J. \& Postgate, J. R. (I97I). Environmental effects on the growth of nitrogen-fixing bacteria Proceedings of the Fifth International Symposium on Continuous Culture of Micro-organisms, Oxford. (In the Press.)

MacLennan, D. G. \& Pirt, S. J. (1966). Automatic control of dissolved oxygen concentration in stirred microbial cultures. Journal of General Microbiology 45, 289-302.

Maclennan, D. G. \& Pirt, S. J. (1970). The dynamics of decane and glucose utilization by a Pseudomonas sp. in batch and chemostat cultures under controlled dissolved oxygen tensions. Journal of Applied Bacteriology 33, 390-396.

Moss, F. J. (1952). The influence of oxygen tension on respiration and cytochrome $a_{2}$ formation of $E$. coli. Australian Journal of Experimental Biology and Medical Science 30, 53I-540.

Moss, F. J. (1956). Adaptation of the cytochromes of $A$. aerogenes in response to environmental oxygen tension. Australian Journal of Experimental Biology and Medical Science 34, 395-406.

Moss, F. J., Rickard, P. A. D., BEECH, G. A. \& BuSH, F. E. (1969). The response by micro-organisms to steady state growth in controlled concentrations of oxygen and glucose. I. Candida utilis. Biotechnology and Bioengineering $\mathrm{rr}, 56 \mathrm{I}-580$.

WIMPENNY, J. W. T. (1969). Oxygen and carbon dioxide as regulators of microbial growth and metabolism. Symposium of the Society for General Microbiology 19, I6I-197.

ZoBell, C. E. (1970). Pressure effects on morphology and life processes of bacteria. In High Pressure Effects on Cellular Processes, pp. 85-130. Edited by A. M. Zimmerman. New York: Academic Press. 